\title{
MeteorQuest - Bringing Families Together Through Proxemics Play In A Mobile Social Game
}

\author{
Rasmus Rosenqvist, Jannik Boldsen, Eleftherios Papachristos, Timothy Merritt \\ Human Centered Computing, Dept. of Computer Science, Aalborg University \\ Aalborg, Denmark \\ rasmuslundrosenqvist, jannikboldsen \{@gmail.com\}, papachristos, merritt @@cs.aau.dk\}
}

\begin{abstract}
Smartphones support gaming, social networking, real-time communication, and individualized experiences. Children and parents often take part in digital experiences with distant friends while isolating themselves from co-present family members. We present MeteorQuest, which is a mobile social game system aimed to bring the family together for location specific game experiences through physical play. The system supports group navigation by mapping screen brightness to the proximity to various ingame targets. Mini-game stages were designed together with interaction designers to encourage physical and social interaction between the players through group puzzles, physical challenges of dexterity and proxemics play. We conducted an exploratory study with three families to gain insights into how families respond to mobile social game features. We studied their socio-spatial arrangements during play and navigation using the lens of proxemics play and provide implications for the design of proxemic interactions and play experiences with families.
\end{abstract}

\section{Author Keywords}

F-formations, Proxemics, Proxemics play, Forcedcollaboration, Competitiveness, Intergenerational play, Location-based games.

\section{INTRODUCTION}

With the rise of personal communication technologies such as smartphones, tablets and social media, family members are offered many ways to stay in touch and communicate with each other. However, uniting the family through these technologies is not an easy design case as children and parents are drawn to different applications that are most suited to their individual interests and not focused on supporting family experiences. When the family members retreat into their favorite apps and games, it is less surprising that families may be seen together physically in public, yet each focused on their own corner of the digital

Permission to make digital or hard copies of all or part of this work for personal or classroom use is granted without fee provided that copies are not made or distributed for profit or commercial advantage and that copies bear this notice and the full citation on the first page. Copyrights for components of this work owned by others than ACM must be honored. Abstracting with credit is permitted. To copy otherwise, or republish, to post on servers or to redistribute to lists, requires prior specific permission and/or a fee. Request permissions from permissions@acm.org.

CHI PLAY'18, October 28-31, 2018, Melbourne, VIC, Australia.

(C) 2018 Copyright is held by the owner/author(s). Publication rights licensed to ACM. ACM 978-1-4503-5624-4/18/10...\$15.00

DOI:http://dx.doi.org/10.1145/3242671.3242685 world. This isolation in the digital experiences can have negative repercussions for the family with members feeling "alone together" [50]. In light of the concerns for social isolation, some parents wish to monitor and control their children's experience with media and screen time [30]. Aside from directly limiting exposure to digital experiences, there have been increasing examples of games designed to bring players together for rewarding shared experiences. Pokémon Go [35] brought many people out into the world to specific locations, and while players often reflected on the enjoyment of the physical activity involved in walking together, the play was largely an individual activity [43].

In recent research on intergenerational family entertainment, [8] various strategies for designing technology for the family suggest various techniques that have led to positive social experiences. There have been recent examples of mobile social games attempting to elevate the social experiences through the gameplay $[18,19]$ and play experiences focused on the physical environment and co-players enabled through innovative uses of the sensors and actuators available in smartphones and other mobile devices [32]. We took inspiration from GlowPhones [32] which utilized smartphones in non-traditional ways to move focus away from the high resolution screen and out into the players' surroundings. That game system encouraged proxemics play with teams of two co-players with findings that suggest simple techniques to encourage social play. In the present paper, we extend the overall concept of GlowPhones and explore design choices that might support intergenerational family play experiences. To support this agenda, we conducted three design workshops with 13 interaction designers to design game features that focus on activating family interactions. The resulting game involved light based navigation and three minigames supporting a play experience for four players within the family including a mix of parents, children and other family relations and extended families. We conducted exploratory studies with three families in two public parks. The findings from the study are analyzed through the lens of proxemics play and intergenerational interaction, which is synthesized into implications for the design of proxemic interactions and play experiences for families. 


\section{RELATED WORK}

The research that informs our work involves family communication, location-based social games, proxemics play and low-resolution displays.

\section{Family communication and interaction}

Research efforts investigating how technology could improve intra-family relationships and communication has resulted in a multitude of applications focused around the domestic realm. Initially, the majority of research was focused on Computer-Mediated Communication aiming to support geographically distanced family members in their need to stay connected $[2,13,4]$. Apart from typical communication platforms (e.g. Video Conference, Instant Messaging, Social Networking Sites) other examples include remote presence [43,21] and awareness systems $[34,38,5]$. However, in recent years the research focus has been expanded to include studies that examine the impact of technology on everyday practices of co-located family members. Examples of research conducted in this space include technology to support family collaboration to complete tasks in a household [44] as well as collaborative organization of household routines [42,7,31].

There has also been a significant amount of interest around technologies that could trigger interactions among colocated family members. For example, "TableTalk" [13] is a system that transforms personal devices into a shared display on the table that stimulates conversation, bonding and socialization between family members during mealtime. Also focused on enriching family interaction during meals was a connected tableware system developed by Joi et al. [21] that encourages children to eat their vegetables and at the same time interact and communicate with their parents while playing a game. These two examples both offer an alternative use of smart devices to encourage social interaction between family members during everyday activities.

Another vein of research investigates the role of technology as a catalyst for communication between intergenerational family members through games and digital entertainment. Games have been developed to facilitate family interaction over a distance (e.g. QQFarm [5], Virtual Box [10]) as well as for families that live close together (e.g. Age Invaders [12], Save Amaze Princess [29], Xtreme Gardener [37]). Resent research suggest guidelines for designing digital games for intergenerational families [8] which includes: prioritizing physical and mixed-reality games, having a player-centered approach and enabling passive/watching play. Interestingly, physical and mixed reality location based games, even if they have not been developed specifically with families in mind, such as Pokémon Go gained recently significant popularity among children and parents alike $[39,45]$.

\section{Location-based games}

There are various examples of location-based games that offer examples for design and provide insights into techniques of supporting play in games where the user positioned in outdoor space is tracked in real-time and utilized to progress in the game [45]. Body position within closed spaces has also been explored, relying on the players to orient and position themselves relative to each other in order to explore and progress in the game [25]. More recently, Pokémon Go is an augmented reality game in which players use their mobile devices with typical built-in sensors (e.g. GPS, camera) to navigate a virtual world by moving in the real world [43]. While the actual goal of the game is to capture virtual monsters, some of the reasons that made this game so popular was that it promoted outdoor physical activity, opportunities for social bonding and exploration $[39,45,35,1]$.

Research on collaborative learning and social interactions in alternate reality games [3] suggest the potential to influence the interactions between players in a positive way [48]. However, safety concerns arose with Pokémon Go among parents related to their children walking around focused on their screens without paying attention to their surroundings [43]. This highlights a disconnect between the physical and virtual worlds that can be problematic at times leading to players tuning out the real world while engrossed in the game. Another location-based game aimed to move player focus away from their screen while also using their mobile phones to navigate and engage in physical play in the real world [32]. In that game, GlowPhones, players utilized their mobile phones in the darkness of night as lowresolutions projectors to light up their immediate surroundings for guidance, while the on board Inertial Measurement Unit (IMU), GPS, and other onboard sensors supported collaborative physical and social play in a public forest.

\section{Proxemics Play}

In GlowPhones [32], unique socio-spatial configurations of players were observed and analyzed providing insights into techniques of encouraging proxemics play between two players. Proxemics involves the study of how people manage their interpersonal space [15]. There are four proxemic zones that have been used to identify how the proximity between people is managed based on the social relations and context: intimate zone (within $0.5 \mathrm{~m}$ ) involve touch and generally reserved for intimately related individuals, personal zone (between $0.5-1.2 \mathrm{~m}$ ) in which close interpersonal exchanges occur, social (between 1.2 $3.6 \mathrm{~m}$ ) is the zone in which much social interactions occur and the public zone (between 3.6 - 7.6m). Proxemics play as described by F. Mueller et al. [33] involves designing for play experiences by encouraging players to become aware of, to cross, and to explore different proxemics zones through activities supported by interactive technologies.

Facing formations (F-formations) [23] further examine spatial arrangements and have been used as an analytical lens to describe social behavior. Facing formations are formed whenever two or more people arrange themselves, so that their transactional segments overlap, creating a space in the middle called the o-space [14]. Every F- 


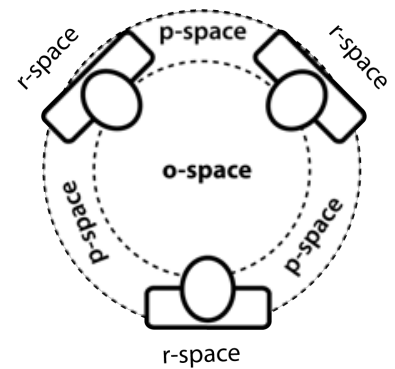

Figure 1. Illustration of the three spatial domains in a facing formation [24].

formation has three distinct spatial domains, o-space, $\mathrm{p}$ space and r-space. The space occupied by the participants is called the p-space and the area outside of the p-space is called the r-space [21] (see Figure 1).

\section{Low-resolution displays}

Marshall McLuhan's claimed that the "medium is the message" [31] suggesting that the nature of the communication channel influences the reception or understanding of the message communicated. Various research strands have explored low-resolution communication and the ways people adjust and utilize the media. Even single-bit communication tools have been found to be useful in encouraging intimate partners to find rewarding communication $[22,37]$.

Gaver et al. described various ways in which ambiguity can be used as a resource for design including ambiguity of information [14] In GlowPhones, the low-resolution navigation techniques encouraged players to explore and make sense of the physical surroundings, and also encouraged various spatial configurations as players tried to understand the low-fidelity navigation queues [32].

\section{DESIGNING A LOCATION-BASED MOBILE SOCIAL GAME FOR FAMILIES}

There has been much research on family communication and interaction over a distance as well as co-located interaction supported by mobile technologies. There are also many examples of location-based games that involve socio-spatial configurations integrated into the play experience and techniques for activating proxemics play. In addition, work utilizing ambiguity and low-resolution displays has been used to move focus away from the screen and onto the co-players and their surroundings to support playful exploration of the physical world.

Inspired by research on location-based experiences and a focus on physical interaction design, we developed

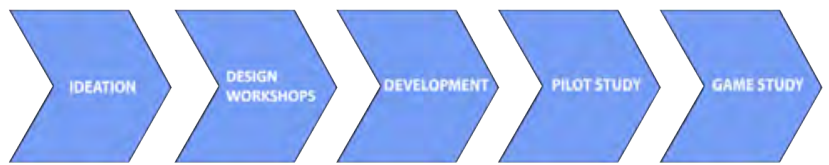

Figure 2. Overview of the process starting with an ideation phase and ending with a game study with families.
MeteorQuest, a family oriented mobile social game. Extending the work of GlowPhones [32], in a MeteorQuest game session, four players are guided through real-world locations, and along their journey, they are faced with minigames they must complete together. Designing and evaluating the game involved five phases, as shown in Figure 2. Initial ideation and the design direction was informed by theory and lessons learned from the GlowPhones system, especially in respect to the focus on designing for spatial arrangements and proxemics play. Design workshops were used to generate the minigames. Technical development of the mobile game and hardware was completed, followed by a pilot study to prepare for the field tests with families.

\begin{tabular}{|c|c|c|}
\hline Design choices & MeteorQuest & GlowPhones \\
\hline Target group & Families & Friends \\
\hline $\begin{array}{r}\text { Number of } \\
\text { players }\end{array}$ & 4 players & 2 players \\
\hline Narrative & $\begin{array}{l}\text { Find a meteor } \\
\text { and destroy it }\end{array}$ & $\begin{array}{l}\text { Collect space junk } \\
\text { in order to launch a } \\
\text { rocket }\end{array}$ \\
\hline $\begin{array}{r}\text { Development of } \\
\text { minigames }\end{array}$ & $\begin{array}{c}\text { Design } \\
\text { workshops } \\
\text { with experts }\end{array}$ & $\begin{array}{l}\text { Based on own } \\
\text { ideas }\end{array}$ \\
\hline $\begin{array}{r}\text { Physical } \\
\text { objects/props }\end{array}$ & $\begin{array}{l}\text { Light bulbs, } \\
\text { treasure chest, } \\
\text { metal plates, } \\
\text { glowsticks }\end{array}$ & Lanterns \\
\hline Challenge & Adequate & Too easy \\
\hline
\end{tabular}

Table 1. Design choices in MeteorQuest compared to GlowPhones.

\section{Design rationale}

Developing the game involved making choices for design based on the overall goal of bringing families together. Table 1 shows the most important design choices compared to GlowPhones, in order to demonstrate the shift of focus in the two studies. Both studies focus on Proxemics Play, Forced Collaboration and Competitiveness in the design of minigames and the overall game experience. The shift of focus from a two-player to a four-player experience is based on the choice of targeting families. While we are aware of the diversity in family configurations, we conducted studies with families consisting of two parents and one or more children. Going through design workshops we chose three minigames to include in the overall game experience. We developed the narrative of the game to fit well within the physical environment and to properly stage the minigames. In GlowPhones, physical props were embedded in the environment (e.g. lanterns) to provide feedback about game progress and to help players identify game stage locations. However, player feedback suggested the lanterns were not utilized as intended, therefore we wanted to explore other physical objects that can be 
integrated into the play experience. Based on feedback in GlowPhones [32] we focused on raising the difficulty of the

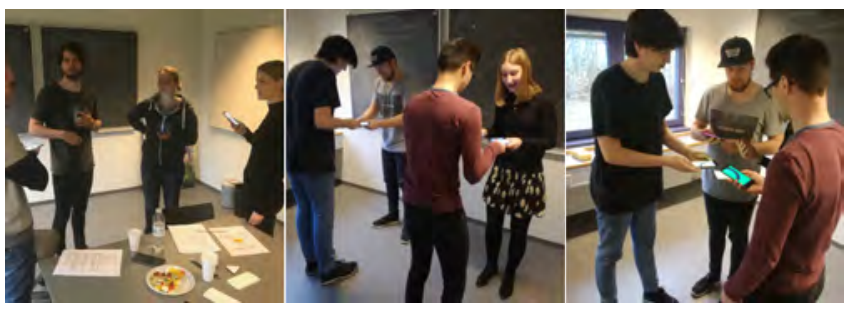

Figure 3. Highlights from design workshops during enactments of minigames that became Left) Puzzle quest, Center) Charge the battery, Right) Meteor chest.

game as the previous minigames were too easy (see Table $1)$.

\section{Design workshops}

We conducted three design workshops with a total of 13 interaction design practitioners that had experience in the design of physical and social play experiences for children. This expert led design process [20] enabled the rapid

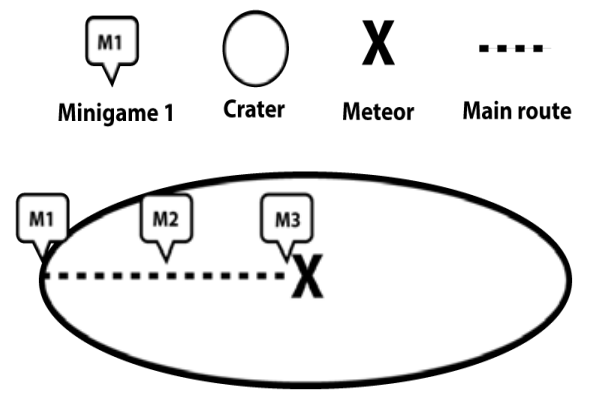

Figure 4. Illustration of the game concept with the meteor narrative.

development of the game platform and minigames, however, we see potential in engaging the users directly in a co-design process [11] with parents and children [52] as well as other family groupings [28] and across generations [51]. The purpose of these design workshops was to design different minigames that could encourage social interaction between the players. This was achieved by designing the minigames for different $\mathrm{F}$-formations [24] and proxemics zones [33], since designing for these concepts has the potential to create different social interactions. As preparation for the sessions we developed six minigames that were shown to the interaction designers. Based on feedback, and our observations during the sessions, we narrowed these six minigames down to the final three, which seem to have the most potential in encouraging social interaction between the players. The design workshops helped us gain insight into how we could design for different F-formations, proxemics zones and how to include other features in order to encourage social interaction even more. Snapshots from the design workshops in Figure 3 show the designers engaged in the workshop activities during the refinement of the three minigames that we used in the field tests

\section{ABOUT THE GAME}

MeteorQuest is a location-based mobile social game for families where the players are guided to a real-world location to find a meteor. On their way to that location the players are faced with three minigames they must complete in order to destroy the meteor, before the radioactivity becomes too strong and destroys the area. The overall game concept with the meteor narrative is illustrated in Figure 4.

\section{Navigation}

In between the different minigames, the players must work together to navigate. For that, the players are divided into two roles: communicators and navigators. The communicators are responsible for passing vital information in relation to the game to the other players. Several times during the game experience, the communicators will receive a call with information about the current stage of the game. This information ideally must be passed on to the other players. This means, that the navigators are the only ones that know where the group has to go, and the communicators are the only ones who know what they have to do, making the two roles dependent on each other, in order to complete the game. The rationale behind designing the two roles is based on providing unequal information to the players that enforce collaboration, which has been shown to encourage social interaction [1]. The intention of this design choice is to encourage the players to navigate and explore the game together as a group.

The navigators can navigate using screen glow intensity, which is presented in GlowPhones [32] as a way of navigating with a smartphone device that utilizes low resolution light. The source code from GlowPhones was made available and we used the same logic for the navigation method. As in the previous system, if the screen of the device is oriented towards the ground, the screen glow intensity navigation is activated and if the screen is rotated upwards the screen turns black. The screen glow intensity navigation method utilizes the brightness and color of the smartphone screen to indicate to the player, if they are getting closer or further away from the target, as shown in Figure $5 \mathrm{~b}$ a green glow signals approaching the target, and red (Figure 5a) indicates moving away from the target.

\section{Minigames}

The three minigames are now described noting the design focus as well as the F-formations and proxemics zones they are intended to explore. For a summary, please refer to Table 2. 


\begin{tabular}{|l|r|l|}
\hline Game stage & Design focus \\
\hline Navigation & $\bullet$ & $\begin{array}{l}\text { Unequal access to } \\
\text { information }\end{array}$ \\
\hline Puzzle Quest & $\bullet$ & $\begin{array}{l}\text { Transition from large to } \\
\text { small o-space }\end{array}$ \\
& - & $\begin{array}{l}\text { Crossing different } \\
\text { proxemics zones }\end{array}$ \\
\hline $\begin{array}{l}\text { Charge the } \\
\text { Battery }\end{array}$ & $\bullet$ & $\begin{array}{l}\text { Face-to-face F-formation } \\
\text { Intimate proxemics zone }\end{array}$ \\
\hline Meteor Chest & $\bullet$ & $\begin{array}{l}\text { Challenging cultural } \\
\text { norms }\end{array}$ \\
& $\bullet$ & $\begin{array}{l}\text { Small o-space } \\
\text { Intimate proxemics zone }\end{array}$ \\
\hline
\end{tabular}

Table 2. Overview of the three minigames and their design focus in relation to $F$-formations and proxemics zones.

\section{Minigame 1: Puzzle Quest}

Four light bulbs with approximately 4 meters between them form a square formation. Each player can unlock a unique piece of a sound file by standing nearby one of the 4 light bulbs. The sound file can only be played, while the players are at the light bulb. Together as a group, they need to decide how to join the sound clips together into one understandable message, which provides a clue about where to find the next minigame. The idea about positioning the light bulbs away from each other is to split up the group and observe how this affects the interaction and communication between players. In addition, Puzzle Quest also explores different spatial domains as well as the transitioning of the players between proxemics zones.

\section{Minigame 2: Charge the Battery}

Because the players are getting closer to the meteor, the radiation from the meteor is getting stronger, which drains the battery of their protective suits. In order to get closer to the meteor, they have to recharge their batteries. Players must cooperate in two groups of two. Each of these dyads have to share their phones physically by placing their thumbs on the marked areas on the screens of the phones. They must then shake the phones up and down vigorously to charge the virtual battery. This minigame explores a face-to-face F-formation in combination with the intimate and personal proxemics zone. This technique of requiring physical collaboration to charge a battery has been useful in

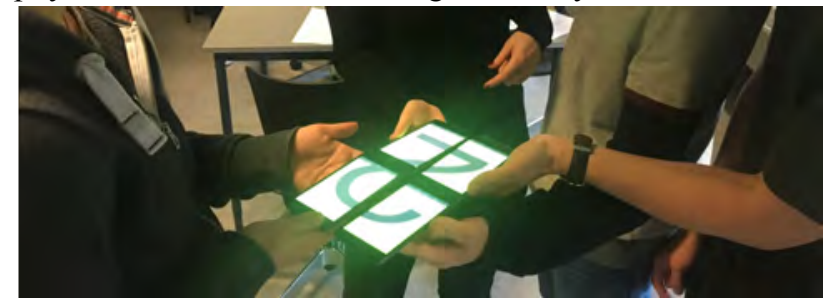

Figure 6. Design workshop developing Minigame 3, unlocking the meteor chest.

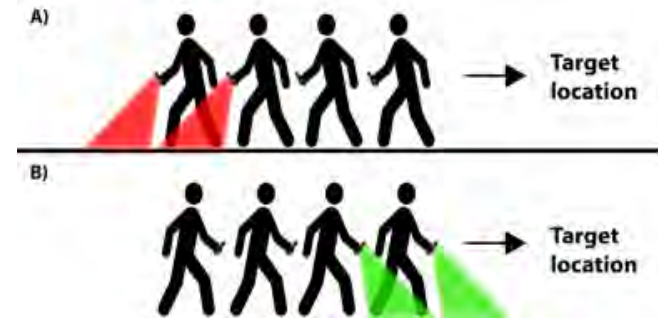

Figure 5. Illustration of the screen glow intensity navigation method with a) red screen glow when moving away from the target and b) green screen glow when approaching the target

other mobile social games including Hotaru [1], which required players to collaborate with body movements and gestures.

\section{Minigame 3: Meteor Chest}

The players have now reached the final location, and they now need to unlock a chest that destroys the meteor. In front of the players is a chest and a four-pin lock code. Each player is provided with four different images that they can shuffle between by flipping their device. As shown in Figure 6, players move their phones together in order to recreate the full image showing a number. Through the design workshops, we found that players would often stand apart from each other and would glance across to other players. We wanted to encourage the players to move closer together physically; therefore, the images were blurred until the player moves their mobile device to rest immediately above the meteor chest. This was enabled using the magnetic field sensor of the mobile devices.

The background color of the images corresponds to one of four colored lock tumblers. Re-creating all the four images will give the players the full combination of numbers in order to open the chest and win the game and destroy the meteor. The game explores a small o-space in combination with the intimate and personal proxemic zone.

\section{FIELD TEST}

Utilizing MeteorQuest as an experimental game platform, we conducted three game studies with three different families in two public city parks. Data was gathered using smartphone log files, socio-spatial observations, Game Experience Questionnaire (GEQ) ratings, and post-game interviews.

\section{Participants}

Three families of four, a total of 12 participants, took part in the study, ranging from 10 years old to 57 years old, consisting of five males and seven female participants. Two of the families included two parents and their two children, while a third included parents, their one child, and niece (cousin of child) as shown in Figure 7. 


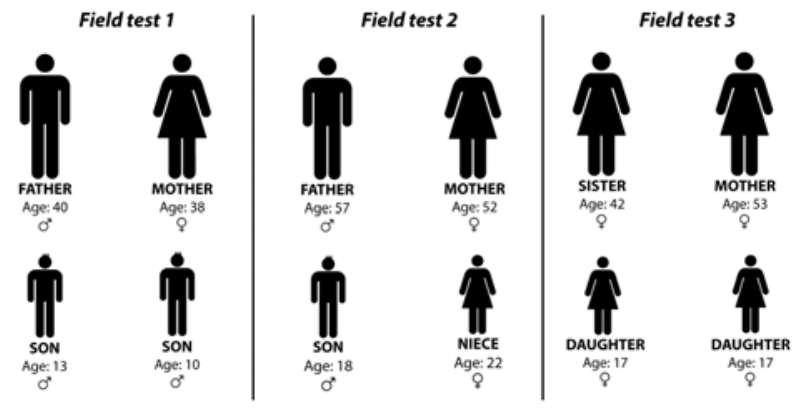

Figure 7. Illustration of the three different family constellations that participated in the studies.

\section{Study sessions}

Each of the study sessions lasted approximately one hour: 30 minutes of gameplay, 15 minutes for filling in the GEQ and 15 minutes for the post-game interview. The sessions started when the families met the researchers at the public park, at which point they were introduced to the game concept, narrative, and basic navigation methods. Furthermore, acceptance from the participants to take pictures and record audio was gained shortly after the introduction. Four smartphones with MeteorQuest installed, were then distributed to the players to begin the game. During the game experience, a study facilitator kept close to the group to be available for inquiry and to take pictures. A second study facilitator walked further behind the group and could control the start of the minigames in the case there should occur errors, e.g. to reset the current minigame. Both facilitators observed the players throughout the game sessions with a special focus on spatial arrangements of the participants proxemic zones and occurrences of F-formations. The players were unaware that we were observing spatial behavior.

\section{RESULTS}

The game study revealed, that overall, the participants enjoyed the game experience and had a good time playing the game. Although the low-light conditions result in poor image quality, highlights from the games sessions are shown in Figure 8. We will examine the feedback from GEQ and the open discussions we had we the participants after each game session, in order to shed light on how a game like MeteorQuest can enhance social interaction between family members. Observations during gameplay

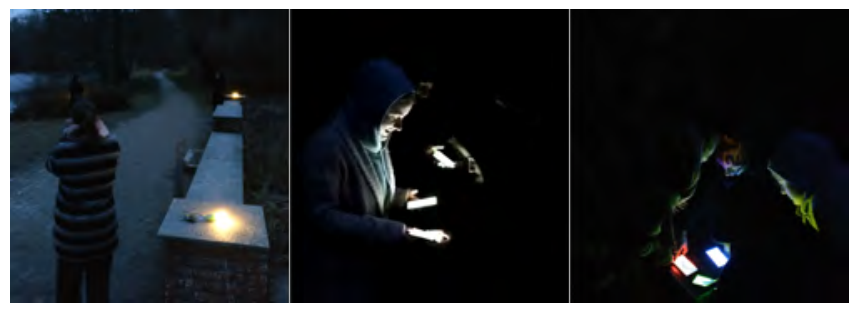

Figure 8. Highlights from game study sessions during minigames that became Left) Puzzle quest, Center) Charge the battery, Right) Meteor chest. were analyzed in terms of proxemic configurations of people, technology and physical space. F-formations were used to analyze the social play experience from a spatial perspective, highlighting how players organized themselves during competitive and collaborative play ranging from social to more intimate configurations

\section{Location data}

While the participants played the game, we logged their location data to be able to analyze how well the navigation methods worked in relation to game completion and the exploration of the players' surroundings. Figure 9 shows a heatmap of one of the participants playing the game in the city of Randers, Denmark and another participant playing the game in the city of Silkeborg, Denmark. As our goal is to enhance social interaction and examine group dynamics in families, we wanted the participants to navigate together as a group and not individually. For this we divided them into two roles: navigators and communicators as explained in the Game study section, so that they were forced to navigate and explore together. We didn't want to limit their exploration of the game and environment as this was considered an important part of the game experience. We managed to get all the participants to navigate and explore together as a group as intended, which we observed had a positive effect on the interaction between the participants. The communicators were given information by the game about how the navigators where able to navigate, and the navigators would lead and show the way for the communicators. This dependency between the two roles made the groups stay together during navigation and the exploration of the game. As shown in Figure 9, the participants stayed on the path and we believe there is room for even more exploration of surroundings. For future iterations, focus could be on how to allow for better exploration of surroundings by working on existing navigations methods or even create new ones.
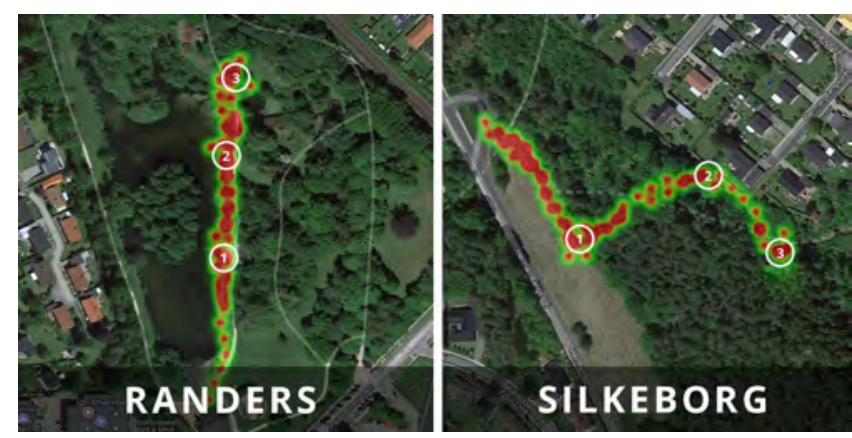

Figure 9. Heatmaps of player movement during the user study in Randers and Silkeborg (towns in Denmark). Stage 1: Puzzle quest, Stage 2: Charge the Battery, Stage 3: Meteor Chest.

\section{Game Experience Questionnaire}

A summary of the results from the Game Experience Questionnaire will be presented followed by an analysis of the most interesting findings. 
All the participants seemed to enjoy the game based on the high average score of positive affect $(\mathrm{M}=3.58, \mathrm{SD}=0.56)$ and the low average score of negative affect $(\mathrm{M}=0.13, \mathrm{SD}$ $=0.39)$. This is also reflected in the high average score in flow $(\mathrm{M}=2.37, \mathrm{SD}=1.54)$ and the low average score in annoyance $(\mathrm{M}=0.56, \mathrm{SD}=0.73)$. The participants felt challenged $(\mathrm{M}=1.62, \mathrm{SD}=1.19)$ by the game at levels higher than GlowPhones [32] yet competent $(\mathrm{M}=3, \mathrm{SD}=$ 0.84 ) playing the game, at levels comparable to previous games [34].

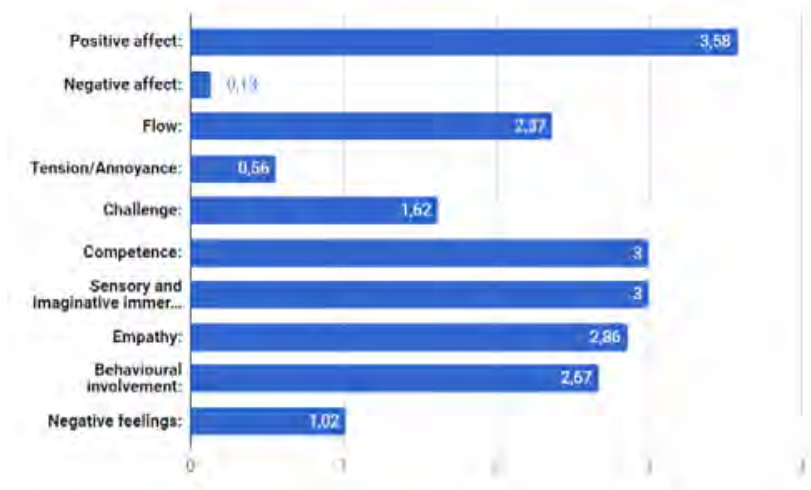

Figure 10. Average component scores from Game Experience Questionnaire.

The participants generally felt sensory and imaginative immersion in the game $(\mathrm{M}=3, \mathrm{SD}=0.89)$. The high average score in empathy $(\mathrm{M}=2.86, \mathrm{SD}=1.07)$ and behavioral involvement $(\mathrm{M}=2.67, \mathrm{SD}=1.13)$ indicates that the participants were socially involved and emotionally invested in each other. Generally, they felt almost no negative feelings towards each other $(\mathrm{M}=1.02, \mathrm{SD}=1.43)$. Based on these results our design rationale seemed to have worked and our goal of creating joyful social experiences seemed to have been reached. Figure 10 illustrates the average component scores from each module.

As presented in our design rationale we wanted to raise the difficulty of the game, based on feedback in GlowPhones [32]. The "challenge" component scores suggest that players found MeteorQuest challenging - overall challenge scores were higher than in GlowPhones. There is a bigger deviation in scores compared to GlowPhones. Parents generally rated the experience more challenging $(\mathrm{M}=2.1$, $\mathrm{SD}=1.07)$ than the younger participants $(\mathrm{M}=1.1, \mathrm{SD}=$ 1.09). The children generally felt more competent playing the game (M $3.4=, \mathrm{SD}=0.67)$ whereas the parents reported lower competence scores $(\mathrm{M}=2.6, \mathrm{SD}=0.81)$.

\section{Social interaction and navigation}

The overall game experience consists of a narrative focused on finding and destroying an imaginary meteorite, which involves navigating to key locations and completing the three minigames as a team. To encourage social interaction between the players, each game stage was designed to form certain F-formations and place the players in specific proxemic zones. The following sections will describe the observed behaviors during the game stages. Here, emphasis will be put on findings that influenced the interaction between the participants and how each game stage succeeded in creating the desired F-formations and in utilizing the different proxemic zones.

The navigation and delegation of roles was designed to force communication between the players by providing unequal access to information. Naturally the navigators would lead the way, as illustrated in Figure 5, with the two communicators walking behind them. Communicators and navigators would converse almost exclusively with each other during navigation, yet would communicate with the whole team when they reached a mini-game stage. We see potential to explore techniques for encouraging communication across the player roles in future work.

\section{Minigame 1: Puzzle Quest}

This game was designed to let the players cross and explore different proxemic zones, as suggested by F. Mueller et al. [33], and have them transition between a large and a small o-space (see Table 2).

We managed to have the players start with a distance of 4 meters between them, creating a large o-space, but they were reluctant to leave their position and explore other proxemic zones. This resulted in minimal interaction between the players, and we observed how they easily turned their backs on each other facing the r-space instead of facing each other. The participants would stay at their position for a couple of minutes, before getting frustrated by the lack of progress in the game, before finally taking action and leave their position. We observed how some of the players would gather in a smaller o-space to figure out the puzzle, but still with one or two players staying at their start position. Only at the very end, all the players would leave their position to gather in a smaller o-space, and this was typically when they managed to solve the puzzle. We observed how the transition from a large to a small o-space, public to an intimate proxemic zone, had a positive effect on the social interaction between the players, where they would start to figure out how to complete the game. This is based on the increased communication between the players that occurred as soon as the o-space between them would get smaller.

Even though the game design didn't intuitively transition the players from a large- to a small o-space, they seemed to enjoy the game and they liked the idea about getting unique information as an individual and then solve a task together as a group. When asked afterwards about the game, one of the participants links this experience to her work:

"To me it was the spread of responsibility in the game that was fun, because you can relate it back to your job, where you have to work together and collaborate in order to complete the task at hand."

\section{Minigame 2: Charge the Battery}

This game was designed to form face-to-face formations in the intimate zone while challenging the players' cultural 
norms, as suggested by F. Mueller et al [33], according to normal behavior in a public park (see Table 2).

The participants formed the intended F-formations, as illustrated in Figure 13, and this seemed the most enjoyed minigame, based on the players' reactions while playing it. Overall, they laughed, smiled and started competing against each other vigorously. When asked afterwards, about the game, one of the participants said:

"It was a very good and fun game due to the difficulty level, but also because that it was both a shared and competitive experience"

By a shared and competitive experience, the participant referred to the two groups of two that formed from the group of four. The players in each group of two had to collaborate to move the phone in a steady and coordinated motion, but then competition between these groups would arise quickly and without prompting - the groups competed to charge the battery the faster than the other dyad.

We observed, by challenging the participants cultural norms by having them do silly motions to charge the virtual battery on their screen, that they would naturally start laughing and it would raise the mood of the group. None of the participants were reluctant to do the motions required by the minigame, as they were doing it together with their family, which we believe made them feel less reluctant to do something silly.

\section{Minigame 3: Meteor Chest}

This game was designed to keep the players in a small ospace in the intimate zone. Throughout the three game studies, we observed the players of every group showing feelings of both frustration, happiness, relief end enjoyment while playing this game. All the players positioned themselves close to each other during this mini-game, forming a circular F-formation.

Interaction and communication between the participants were observed to be at the highest in this minigame, which might be explained by the significantly small o-space of the formation, resembling an intimate proxemic zone, which is described as a shared space where the players expect interpersonal engagement and intimacy [24].

Each of the four players used the mobile phone assigned to them as their personal game device. However, we observed behaviors in the game in which players would offer their mobile phone to the wider team - effectively transitioning the smartphone from a private to a shared device. When a phone was placed on the chest in front of them, it suddenly became a shared object, and it was acceptable to move it and control it by the other players. The transformation of the phone from a private to a shared object inherently led the group to interact and communicate with each other.

\section{DISCUSSION}

Our aim in this paper has been to highlight how a locationbased mobile social game, drawing on previous experiences from GlowPhones, theories of proxemics play, and sociospatial concepts can bring families together. We want to offer an alternative way for families to socialize, which could prove useful in future research and development of mobile social games. We now discuss key findings in relation to difficulty of the game, shared space and shared display and proxemics play. Furthermore, implications for design will be presented and discussed in relation to relevant literature.

\section{Difficulty of the game}

One of the more salient findings of this paper is in relation to the general difficulty of the game. One of the main concerns with GlowPhones was noted in the GEQ analysis and stated in the feedback from participants, that the game was not very challenging [32]. Considering this critical feedback, we worked to develop MeteorQuest so that it would not be too easy nor too difficult [40]. We wanted to ensure that players of all levels would enjoy the game experience. Throughout our game studies, our initial impression was that the game was too difficult, due to the frustrations, which emerged and heated discussions among the families. However, feedback in the post-game interviews showed that the families enjoyed being frustrated from time to time.

"Meteor chest was by far the most challenging game, but this was a good thing" -P3

Manipulation of the mobile phones was something the children generally understood and we noticed in each session, the children of the family would be required to help the parents at least once to understand how to complete a minigame.

\section{Shared space and shared display}

During the different stages of the game, families tended to communicate and interact most actively in the last minigame called "Meteor Chest". Players needed to put all their devices close together in order to form a shared display revealing a full image. In the post-game interviews, family members pointed to this game as being the minigame where they had to cooperate the most.

Throughout the minigame we observed how the family members shared the devices between each other. Another study, which has concentrated on bringing families together with the use of technologies in collocated shared settings, is the paper TableTalk [13]. In that study as well as in MeteorQuest, moving the device from the players' own possession and onto a shared space seemed to grant the whole family temporary ownership and access to all of the devices. This highlights the cooperation and sense of togetherness between coplayers. For our case, this was evident in all of the groups but especially for group 3. In that group, all of the family members placed their devices onto a shared space where they immediately began to move and rotate each other's devices. 


\section{Proxemics Play strategies}

F. Mueller et al. [33] identifies four design strategies for Proxemics Play that can facilitate engaging play experiences. These strategies will now be discussed in relation to some of our key findings. One of those strategies suggests challenging proxemics' cultural norms. In minigame 2, "Charge the Battery", the players have to charge a virtual battery on their screen by facing each other two and two and shake the phone up and down. By challenging the players' cultural norms of normal behavior in a public park, we observed how they enjoyed and engaged themselves in the experience, supporting the claim that challenging cultural norms can be a liberating experience [33].

Another strategy suggests facilitating bodily movement by supporting the exploration of proxemics zones by making movement within or across proxemic zones engaging [33]. In the same game, "Charge the Battery", we explored this strategy by making the participants do silly motions, while sharing their intimate space with another player. Because the game design put them together two and two, we observed how they would naturally start competing each other, supporting the claim that bodily movement can facilitate emotional experiences.

A third strategy suggests facilitating players' awareness of zones by making the players aware that they can explore these zones freely. In minigame 1, "Puzzle Quest", we had each player go to a certain location, approximately four meters from the other players, where they would unlock a unique sound file. To complete the game, they had to puzzle together their sound files into one understandable message. The game design made the players explore different proxemic zones, by distancing them from each other. After a while, communicating over distance, the players would get frustrated and start exploring other proxemic zones by going closer together. If the players forgot what their part of the message said, we observed how they naturally went back to their unique location to hear it again, thereby feeling free to explore different zones when needed.

The last strategy suggests supporting discovery of proxemics zones' blurry borderlines, where we observed in minigame 3, "Meteor Chest", how this strategy supports engaging play experiences. In "Meteor Chest", each player receives one quarter of an image on their screen, and by holding their phones close together, the full image can be seen. The full image provides a code for the players they have to use to unlock a chest placed in front of them (see Figure 6). From the design workshops, we observed how the players were able to predict the full image by looking at their own screen, which diminished the need for them to work together. Therefore, we designed the game to use the magnetic field sensor in the phones to blur the image unless it is placed on a metal object. We placed metal plates on top of the chest in front of them, forcing them to place their phones on the chest to see the image on the screen. By making this design choice, we forced the players to place their phones on a shared object in front of them, also blurring the borderlines between proxemic zones. Normally the phone is considered a private device used by the owner, even when interacting in close proximity to others, yet in this minigame, all the phones were moved and adjusted by the players as desired without regard to who it belonged.

\section{Sensitizing concepts for proxemic interactions}

Krogh et al. [27] identifies sensitizing concepts related to socio-spatial configurations of people engaged with colocated people and media. We will discuss our results in relation to two of the most relevant.

In relation to proxemics threshold we found it easy, as technology designers, to change the socio-spatial configurations of the participants while they were playing the game. In each of the game stages, participants readily change their configuration in order to suit the game task. The low threshold observed in MeteorQuest is likely a result of it being a game. This was also described in GlowPhones in relation to players being immersed and engaged in the "magic circle" of the gameworld.

During the game studies, we observed default socio-spatial configurations that emerged when the players would navigate - the players would walk together two and two (see Figure 11). This seemed especially stable and even if the group temporarily broke formation if one member stopped or would walk off the path, the two and two formation would soon resume, as evidence of proxemics gravity [27].

\section{Implications for proxemic interactions}

The main contribution of this paper is implications for design that future researchers and designers can use when designing social games for intergenerational families. These implications are derived from fieldwork data from three game studies and will be presented as a list of short descriptions [41] created after an analysis of the gathered fieldwork data. Table 3 gives an overview of these design implications.

\section{CONCLUSION}

MeteorQuest is a location-based mobile social game that aims to bring families together in a physical play experience. We showed how designing for Proxemics Play, including f-formations and proxemic zones, could encourage social interaction between intergenerational family members. Three gaming sessions with three different families playing the game were conducted and implications for design are derived from analyzing fieldwork data.

Some possible limitations in our work include the lack of diversity in families playing the game, and that the game studies could have explored more locations as well as more field tests in general. We are aware of these concerns, however, through our studies, we observed recurring patterns of behavior and we provide initial insights to show how a mobile social game can stage proxemics play experiences and bring families together. 


\begin{tabular}{|c|c|}
\hline Design Implications & Description \\
\hline $\begin{array}{l}\text { Challenge the players' } \\
\text { technical expertise }\end{array}$ & $\begin{array}{l}\text { By challenging the players' technical expertise in the game, they will seek help and guidance } \\
\text { from the other players. } \\
\text { An example is minigame 3, "Meteor Chest", where some of the players didn't know that } \\
\text { smartphones had magnetic field sensors. Therefore, they sought help from the other players. }\end{array}$ \\
\hline $\begin{array}{l}\text { Unequal access to } \\
\text { information }\end{array}$ & $\begin{array}{l}\text { Providing unequal access to information, e.g. by using two or more roles in the game that only } \\
\text { have access to specific information, makes it possible to keep the players together as a group } \\
\text { throughout the game experience. } \\
\text { An example is in between the game stages, where the players are navigating. By dividing the } \\
\text { players into two roles as navigators and communicators with unequal access to information, we } \\
\text { managed to have them explore together. }\end{array}$ \\
\hline Ambiguity & $\begin{array}{l}\text { By designing for ambiguity it's possible to enhance communication between intergenerational } \\
\text { family members. } \\
\text { Navigation was low resolution and ambiguous, which lead to the family discussing and } \\
\text { working together as they tried to navigate between mini-games. }\end{array}$ \\
\hline $\begin{array}{l}\text { Challenge cultural } \\
\text { norms }\end{array}$ & $\begin{array}{l}\text { Challenging the players' cultural norms raises the mood in the group and the desire to } \\
\text { communicate and interact with the other players. Challenging players' cultural norms is also } \\
\text { suggested by F. Mueller et al. [33]. } \\
\text { An example is from minigame 2, "Charge the Battery", where the players are doing silly } \\
\text { motions in a public park to charge a virtual battery on their screens. }\end{array}$ \\
\hline $\begin{array}{l}\text { Force small o-space } \\
\text { with shared display }\end{array}$ & $\begin{array}{l}\text { By providing the players with a shared physical object or display, it's possible to encourage } \\
\text { and even force interaction. } \\
\text { An example is from minigame } 3 \text {, "Meteor Chest", where the players are forced to place their } \\
\text { phones on a shared object in front of them to create a shared display. }\end{array}$ \\
\hline $\begin{array}{l}\text { Transform private } \\
\text { device to shared } \\
\text { object }\end{array}$ & $\begin{array}{l}\text { Instead of keeping the players' smart phone as a private object, transforming it to become a } \\
\text { shared object can encourage interaction and communication. } \\
\text { In "Charge the Battery", by forcing the players to create a shared display, the players would set } \\
\text { the mobile down at which point all players were free to move and reorient any of the devices. } \\
\text { They were treated collectively as a shared object. }\end{array}$ \\
\hline
\end{tabular}

Table 3: Design implications derived from the analysis of fieldwork data to inform the design of social games for intergenerational families.

In future work, additional families will be studied including non-traditional family configurations. We also look forward to future studies involving non-family groups including ice breaking events for corporate team-building [16] and entertainment experiences for non-related friends. This work focused on families as a first step, which was helpful in that participants already know each other and feel comfortable engaging in close physical play experiences together and would be able to articulate the experiences they observed of the others in their session based on past knowledge of each other. We intend to offer this system as an open-source platform so that other researchers can quickly author a new game experience in different locations. We are building a catalog of mini-games to make available in the base platform and means for users to create new mini-games. Furthermore, we are working on improvements to the existing navigation methods and the development of other non-traditional ways to use low resolution light or other actuators on the smart phone to design new methods to navigate.

\section{REFERENCES}

1. Kaho Abe. 2016. Hotaru: The Lightning Bug Game. In CHI Extended Abstracts on Human Factors in Computing Systems, 277-280. http://doi.org/10.1145/2851581.2889472

2. E. Althoff, T., White, R. W., \& Horvitz. 2016. Influence of Pokémon Go on physical activity: study and implications.

3. Elizabeth Bonsignore, Kari Kraus, Ahn June, Visconti Amanda, Ann Fraistat, and Allison Druin. 2012. Alternate Reality Games: Platforms for Collaborative Learning. In Proceedings of the Tenth International 
Conference of the Learning Sciences.

4. Bernheim A J Brush, Kori M. Inkpen, and Tee Kimberly. 2008. SPARCS: exploring sharing suggestions to enhance family connectedness. CSCW '08: Proceedings of the 2008 ACM conference on Computer supported cooperative work: 629-638. http://doi.org/http://doi.acm.org/10.1145/1460563.1460 661

5. B. Chen, Y., Wen, J., \& Xie. 2012. "I communicate with my children in the game": Mediated intergenerational family relationships through a social networking game.

6. X Ciao, A Sellen, A.J Brush, D Kirk, D Edge, and X Ding. 2010. Understanding Family Communication Across Time Zones. CSCW 2010: 155-158.

7. J. Cornejo, R., Tentori, M., \& Favela. Ambient awareness to strengthen the family social network of older adults.

8. Liliana Costa and Ana Veloso. 2016. Being (Grand) Players: Review of Digital Games and their Potential to Enhance Intergenerational Interactions. Journal of Intergenerational Relationships 14, 1: 43-59. http://doi.org/10.1080/15350770.2016.1138273

9. T. Crabtree, A., \& Rodden. 2004. Domestic routines and design for the home.

10. F. Davis, H., Skov, M. B., Stougaard, M., \& Vetere. 2007. Virtual box: Supporting mediated family intimacy through virtual and physical play.

11. Allison Druin. 2002. The role of children in the design of new technology, Behaviour \& Infirmation Technology. Behaviour \& Information Technology 21, 1: $1-25$

12. Kelvin Eng Tat, Khoo \& Merritt, Tim \& David Cheok, Adrian \& Lian, Mervyn \& Yeo. 2007. Age Invaders: User Studies of Intergenerational Computer Entertainment. In Entertainment Computing-ICEC 2007, 231-242.

13. Hasan Shahid Ferdous, Bernd Ploderer, Hilary Davis, et al. 2016. TableTalk: Integrating Personal Devices and Content for Commensal Experiences at the Family Dinner Table. Proceedings of the 2016 ACM International Joint Conference on Pervasive and Ubiquitous Computing, September: 132-143. http://doi.org/10.1145/2971648.2971715

14. William W. Gaver, Jacob Beaver, and Steve Benford. 2003. Ambiguity as a resource for design. Proceedings of the conference on Human factors in computing systems - CHI '03, May: 233. http://doi.org/10.1145/642651.642653

15. E. T. HALL. 1966. The Hidden Dimension.

16. C Handy. 1995. Trust and the Virtual Organization. Harvard Business Review 73, 3: 40-50. http://doi.org/10.1016/0024-6301(95)94284-6

17. Yasamin Heshmat, Carman Neustaedter, Lillian Yang, and Thecla Schiphorst. 2017. Connecting Family Members Across Time Through Shared Media. Proceedings of the 2017 CHI Conference Extended Abstracts on Human Factors in Computing Systems CHI EA '17: 2630-2637. http://doi.org/10.1145/3027063.3053205

18. Katherine Isbister. 2016. Connecting through play. Interactions $23, \quad 4: \quad 26-33$. http://doi.org/10.1145/2946999

19. Katherine Isbister, Kaho Abe, and Michael Karlesky. 2017. Interdependent Wearables (for Play). Proceedings of the 2017 CHI Conference on Human Factors in Computing Systems - CHI '17: 465-471. http://doi.org/10.1145/3025453.3025939

20. Sara Isola and Jerry Alan Fails. 2012. Family and design in the IDC and CHI communities. In Proceedings of the 11th International Conference on Interaction Design and Children - $\quad$ IDC '12, 40. http://doi.org/10.1145/2307096.2307102

21. Yeong Rae Joi, Beom Taek Jeong, Jin Hwang Kim, et al. 2016. Interactive and Connected Tableware for Promoting Children's Vegetable-Eating and Family Interaction. Proceedings of the The 15th International Conference on Interaction Design and Children - IDC '16: 414-420. http://doi.org/10.1145/2930674.2930711

22. Joseph Kaye, Mariah K Levitt, Jeffrey Nevins, Jessica Golden, and Vanessa Schmidt. 2005. Communicating intimacy one bit at a time. CHI '05 extended abstracts on Human factors in computing systems - CHI '05: 1529. http://doi.org/10.1145/1056808.1056958

23. A. KENDON. 1990. Spatial organization in social encounters: The f-formation system. Conducting interaction: Patterns of behavior in focused encounters. 209-238.

24. Adam Kendon. 1990. Conducting Interaction: Patterns of Behavior in Focused Encounters. Cambridge University Press, Cambridge:

25. Eng Tat Khoo, Timothy Merritt, Victor Lim Fei, et al. 2008. Body music. Proceedings of the 2008 ACM SIGGRAPH symposium on Video games - Sandbox '08, March 2014: 35. http://doi.org/10.1145/1401843.1401850

26. Naeun Kim, Boram Yoon, Sam Jin, Hayang Seo, Ohkyun Kwon, and Jinwoo Kim. 2017. Internet of family. Proceedings of the 11th International Conference on Ubiquitous Information Management and Communication - IMCOM '17: 1-9. http://doi.org/10.1145/3022227.3022275

27. Peter Gall Krogh, Marianne Graves, and Kenton O Hara. 2017. Sensitizing Concepts for Socio-Spatial 
Literacy in HCI. Proceedings of CHI 2017: 6449-6460. http://doi.org/10.1145/3025453.3025756

28. Sinna Lindquist, Bo Westerlund, Yngve Sundblad, Helena Tobiasson, Michel Beaudouin-Lafon, and Wendy Mackay. Co-designing Communication Technology with and for Families - Methods, Experience, Results and Impact. In The Disappearing Computer. Springer Berlin Heidelberg, Berlin, Heidelberg, 99-119. http://doi.org/10.1007/978-3-54072727-9_5

29. J. B. Al Mahmud, A., Mubin, O., Shahid, S., \& Martens. 2010. Designing social games for children and older adults: Two related case studies. http://doi.org/2042753018761166

30. M Mazmanian and S Lanette. 2017. "Okay, one more episode": An ethnography of parenting in the digital age. Proceedings of the ACM Conference on Computer Supported Cooperative Work, CSCW: 2273-2286. http://doi.org/10.1145/2998181.2998218

31. Marshall McLuhan. 1994. McLuhan Understanding Media The extensions of man London and New York. Basieexpsispittedu: 318. http://doi.org/10.2307/2711172

32. Timothy Merritt, Christine Linding Nielsen, Frederik Lund Jakobsen, and Jens Emil Grønbæk. 2017. GlowPhones : Designing for Proxemics Play with LowResolution Displays in Location-based Games.

33. Florian Mueller, Sophie Stellmach, Saul Greenberg, et al. 2014. Proxemics play: Understanding Proxemics for Designing Digital Play Experiences. Proceedings of the 2014 conference on Designing interactive systems: 533542. http://doi.org/10.1145/2598510.2598532

34. L. E NACKE, S STELLMACH, D SASSE, and C. A. LINDLEY. Gameplay experience in a gaze interaction game.

35. Inc. Niantic. 2016. Pokémon GO.

36. Rui Pan, Azadeh Forghani, Carman Neustaedter, Nick Strauss, and Ashley Guindon. 2015. The Family Board: An Information Sharing System for Family Members. Extended Proceedings of the Conference on Computer Supported Cooperative Work: 207-210. http://doi.org/10.1145/2685553.2699008

37. J. Rice, M., Tan, W. P., Ong, J., Yau, L. J., Wan, M., \& Ng. 2013. The dynamics of younger and older adult's paired behavior when playing an interactive silhouette game.

38. B Romero, N., Markopoulos, P., van Baren, J., de Ruyter, B, Jsselsteijn, W., and Farshchian. 2006. Connecting the Family with Awareness Systems.

39. E. J. Ruiz-Ariza, A., Casuso, R. A., Suarez-Manzano, S., \& Martínez-López. 2018. Effect of augmented reality game Pokémon GO on cognitive performance and emotional intelligence in adolescent young.

40. Katie Salen and Eric Zimmerman. 2004. Rules of Play: Game Design Fundamentals. The MIT Press.

41. Corina Sas, Steve Whittaker, Steven Dow, Jodi Forlizzi, and John Zimmerman. 2014. Generating implications for design through design research. Proceedings of the 32nd annual ACM conference on Human factors in computing systems - CHI '14: 1971-1980. http://doi.org/10.1145/2556288.2557357

42. M. Saslis-Lagoudakis, G., Cheverst, K., Dix, A., Fitton, D. and Rouncefield. 2006. Supporting awareness and intimacy between distant family members.

43. Hiniker A Sobel K, Bhattacharya A. 2017. "It wasn't really about the Pokémon": Parents' perspectives on a location-based mobile game.

44. Timothy Sohn, Lorikeet Lee, Stephanie Zhang, David Dearman, and Khai Truong. 2012. An examination of how households share and coordinate the completion of errands. Proceedings of the ACM 2012 conference on Computer Supported Cooperative Work - CSCW '12: 729. http://doi.org/10.1145/2145204.2145315

45. Olli Sotamaa. 2002. All The World's A Botfighter Stage: Notes on Location-based Multi-User Gaming. Cultures: $35-44$.

46. L. Taylor, A., and Swan. 2005. Artful Systems in the Home.

47. J. Tollmar, K., and Persson. 2002. Understanding Remote Presence.

48. Lili Tong, Audrey Serna, Simon Pageaud, et al. 2016. It's Not How You Stand, It's How You Move: Fformations and Collaboration Dynamics in a Mobile Learning Game.

49. K. M. Tran. Families, resources, and learning around Pokémon Go.

50. Sherry Turkle. 2011. Alone together: why we expect more from technology and less frome each other. New York : Basic Books, New York.

51. Bo Xie, Allison Druin, Jerry Fails, et al. 2012. Connecting generations: developing co-design methods for older adults and children. Behaviour \& Information Technology 31, 4: 413-423. http://doi.org/10.1080/01449291003793793

52. Jason C. Yip, Tamara Clegg, June Ahn, et al. 2016. The Evolution of Engagements and Social Bonds During Child-Parent Co-design. In Proceedings of the 2016 CHI Conference on Human Factors in Computing Systems - CHI '16, 3607-3619. http://doi.org/10.1145/2858036.2858380 